\title{
Evaluation of Daily Gridded Meteorological Datasets over the Niger Delta Region of Nigeria and Implication to Water Resources Management
}

\author{
Ibrahim Hassan ${ }^{1,2}$, Robert M. Kalin ${ }^{1}$, Christopher J. White ${ }^{1}$, Jamiu A. Aladejana ${ }^{1,3}$ \\ ${ }^{1}$ Department of Civil and Environmental Engineering, University of Strathclyde, Glasgow, UK \\ ${ }^{2}$ Department of Civil Engineering, Abubakar Tafawa Balewa University, Bauchi, Nigeria \\ ${ }^{3}$ Department of Geology, University of Ibadan, Ibadan, Nigeria \\ Email: Ibrahim.hassan@strath.ac.uk, ibzara@yahoo.com
}

How to cite this paper: Hassan, I., Kalin, R.M., White, C.J. and Aladejana, J.A. (2020) Evaluation of Daily Gridded Meteorological Datasets over the Niger Delta Region of Nigeria and Implication to Water Resources Management. Atmospheric and Climate Sciences, 10, 21-39.

https://doi.org/10.4236/acs.2020.101002

Received: November 22, 2019

Accepted: December 20, 2019

Published: December 23, 2019

Copyright $\odot 2020$ by author(s) and Scientific Research Publishing Inc. This work is licensed under the Creative Commons Attribution International License (CC BY 4.0).

http://creativecommons.org/licenses/by/4.0/

\begin{abstract}
Hydro-climatological study is difficult in most of the developing countries due to the paucity of monitoring stations. Gridded climatological data provides an opportunity to extrapolate climate to areas without monitoring stations based on their ability to replicate the Spatio-temporal distribution and variability of observed datasets. Simple correlation and error analyses are not enough to predict the variability and distribution of precipitation and temperature. In this study, the coefficient of correlation $\left(\mathrm{R}^{2}\right)$, Root mean square error (RMSE), mean bias error (MBE) and mean wet and dry spell lengths were used to evaluate the performance of three widely used daily gridded precipitation, maximum and minimum temperature datasets from the Climatic Research Unit (CRU), Princeton University Global Meteorological Forcing (PGF) and Climate Forecast System Reanalysis (CFSR) datasets available over the Niger Delta part of Nigeria. The Standardised Precipitation Index was used to assess the confidence of using gridded precipitation products on water resource management. Results of correlation, error, and spell length analysis revealed that the CRU and PGF datasets performed much better than the CFSR datasets. SPI values also indicate a good association between station and CRU precipitation products. The CFSR datasets in comparison with the other data products in many years overestimated and underestimated the SPI. This indicates weak accuracy in predictability, hence not reliable for water resource management in the study area. However, CRU data products were found to perform much better in most of the statistical assessments conducted. This makes the methods used in this study to be useful for the as-
\end{abstract}


sessment of various gridded datasets in various hydrological and climatic applications.

\section{Keywords}

Climate Research Unit (CRU), Princeton University Global Meteorological Forcing Dataset (PGF), Climate Forecast System Reanalysis (CFSR), Standardised Precipitation Index (SPI)

\section{Introduction}

The accuracy and reliability of climate datasets are crucial for scientific research and hydrologic studies related to climate change impact assessment, numerical weather prediction, flood forecasting, drought monitoring or water resources management [1]. Paucity of data remains a challenging task especially in developing countries and in remote parts of the world where ground-based precipitation measurements, such as radar networks and rain gauges are either sparse or non-existent due to the high cost of establishment and maintenance of the infrastructure [2].

Recently, climate impact studies have become increasingly detailed as global industrialisation results in an unprecedented increase in greenhouse gases concentrations (GHGs), and associated impact on the changing climate [3]. Climate change impact assessment requires climate data at various spatial and temporal scales [4]. Getting data observations at an acceptable spatial resolution is challenging in developing countries, and where available, their quality is either poor or expensive and may poorly represent a study area with large hydroclimatic gradients [5] [6]. To overcome these challenges, researchers resort to the use of multilayer global gridded representations of meteorological data to serve as inputs into climate and hydrological modelling studies [6].

Climate datasets are typically measured in three ways viz: Gauge-Based observations, Satellite Estimates, and Reanalysis datasets [7]. Gauge observations provide relatively accurate and trusted measurements at a single point and are subject to limitations, such as reporting time delays, sparse gauge networks, data gaps, unavailable over many sparsely populated and oceanic areas and limited access to available data [8]. Satellite observations provide broad coverage of global atmospheric parameters with adequate spatial and temporal resolution in un-gauged regions, such as the oceans, complex mountain areas, and deserts. They provide information at regular intervals with uniform spatial coverage but contain non-negligible biases and random errors owing to the complicated nature of the relationship between the observations, sampling, and deficiencies in the algorithms. Reanalysis datasets merge random observations and models that encompass many physical and dynamical processes to generate a synthesised estimate of the state of the system across a regular grid, with spatial homogeneity, temporal continuity, and a multidimensional hierarchy [7]. These datasets are 
classified into regional and global datasets. Regional products are explicitly developed for countries or regions, for example, [9] and [10] developed climate datasets for Asia, and [11] developed for Europe, [12] for Spain, and, [13] for Switzerland.

Different organizations have developed different global datasets such as, the Climatic Research Unit (CRU) [14], Global Historical Climatology Network (GHCN) [15], National Oceanic and Atmospheric Administration (NOAA) [16], Climate Forecast System Reanalysis (CFSR) [17], Princeton University Global Meteorological Forcing dataset (PGF) [18] and Global Precipitation Climatology Centre (GPCC) [19]. These global gridded datasets have different spatial and temporal resolutions. The quality is governed by the data assimilation system, its optimisation and the quality of observation data used [1] [8]. The reliability of the gridded datasets varies with time and regional climate [7]. This makes it necessary to evaluate the capability of gridded data before its application over specific locations.

Recent studies show an increase in the usage of station gauge-based datasets for validating estimates from different interpolated datasets, reanalysis datasets, satellite products and climate models. For example, [5] used gauge-based datasets for comparison of four gridded datasets namely Asian Precipitation Highly Resolved Observational Data Integration towards Evaluation (APHRODITE), Global Precipitation Climatology Centre (GPCC), Centre for Climatic ResearchUniversity of Delaware (UDel); and Climatic Research Unit (CRU) datasets at stations located in the arid, semi-arid, and hyper-arid regions of Balochistan province of Pakistan. [20] used unified rain gauge data with three daily gauge based gridded rainfall datasets, namely the Indian Meteorological Department (IMD), APHRODITE and Climate Prediction centre (CPC) over India. [21] used IMD dataset for comparison of two satellite datasets, namely, GPCP and Tropical Rainfall Measurement Mission (TRMM) [22]. Compared station datasets with two gridded rainfall datasets, namely Climatic Research Unit (CRU), Hydro-Sciences Montpellier (SIEREM) for Burkina-Faso in West Africa.

Considering such diverse use, it is necessary to carefully examine and compare the characteristics and pattern of the gridded datasets. An inter-comparison should analyse the prominent precipitation spell characteristics such as wet and dry spells among the different gridded datasets and importantly, the implications of using these gridded products on water resource management. Variations in frequency, length and intensity of dry and wet spells within predicted datasets often lead to faulty hydrological and agricultural decisions like extreme events estimation, improper selection of crops, incorrect estimation of sowing and harvesting time [23]. Wet spells are prolonged number of wet days and serve as an indicator of flood conditions while Dry spells are prolonged period of dry days, which also serve as an indicator of drought conditions [20]. This information is of prime importance to the hydrologists, agronomist, hydrogeologists and water-resources managers [24] [25] [26] [27]. Standardised Precipitation Index (SPI) is used to identify meteorological wet and drought events from precipita- 
tion time series data and serves as a useful tool in water resource management [28].

Several studies [1] [2] [5] [8] [21]-[30] compared gridded datasets with station measurements, however, no study has been conducted in any part of Nigeria to determine which of the best stable gridded climate products matches well with the observed station datasets, and thus serves as a substitute to the station datasets in this highly data-scarce region. Most previous studies use correlation and error analysis to evaluate the performance of gridded products by comparing them with observed station datasets, but performance assessment of the products based on correlation and error analysis alone can be misleading [5]. This is because the coefficient of correlation is highly sensitive to outliers, hence may not explain the model capabilities fully [31]. The RMSE also varies with the variability in squared errors which reduces its ability to determine the degree to which it reflects average errors and to what extent it reflects variability in the distribution of squared errors [31] [32]. To overcome these drawbacks, indices like mean bias error (MBE) and spell lengths analysis can be used. $\mathrm{MBE}$ is used to analyse the mean in overestimations and underestimations of models. Wet and dry spells analysis are referred to as extended periods of wet and dry days, respectively [20] which is used in this study to compare which of the gridded datasets matches the observed datasets in estimating the wet and dry spells.

This study aims to: 1) to evaluate data from three gauge based gridded datasets (CRU, PGF and CFSR) daily precipitation, maximum and minimum temperature datasets available for the Niger Delta and compares it with observed station datasets to identify their fundamental differences. 2) analyse different spell characteristics and identify prominent differences in the spells of the datasets and 3) use the Standardised Precipitation Index (SPI) to assess the implications of using the gridded precipitation products on water resource management in Nigeria. The results will aid water resource management practitioners in selecting the appropriate gridded precipitation and temperature dataset for studying the best-gridded precipitation and temperature products depending upon the scope and application. This study provides insights into the Spatio-temporal behaviour of these three datasets for extreme events estimation, which in turn will benefit hydrological management over un-gauged or sparsely gauged regions.

\section{Description of Study Area}

The study area located in the Niger Delta part of Nigeria comprises of Bayelsa and Rivers State is presented in Figure 1. The area is low lying drained by Rivers Imo, Aba, Kwa-Ibo, Bonny, and their respective tributaries. The topography of the area under the influence of high coastal tides results in flooding mostly during the rainy season [33]. The climatic condition in the region comprises of the wet seasons (March to October) and dry seasons (November to February) characterised by high temperatures and high relative humidity throughout the year. A short spell of the dry season often referred to as the "August break" caused by 


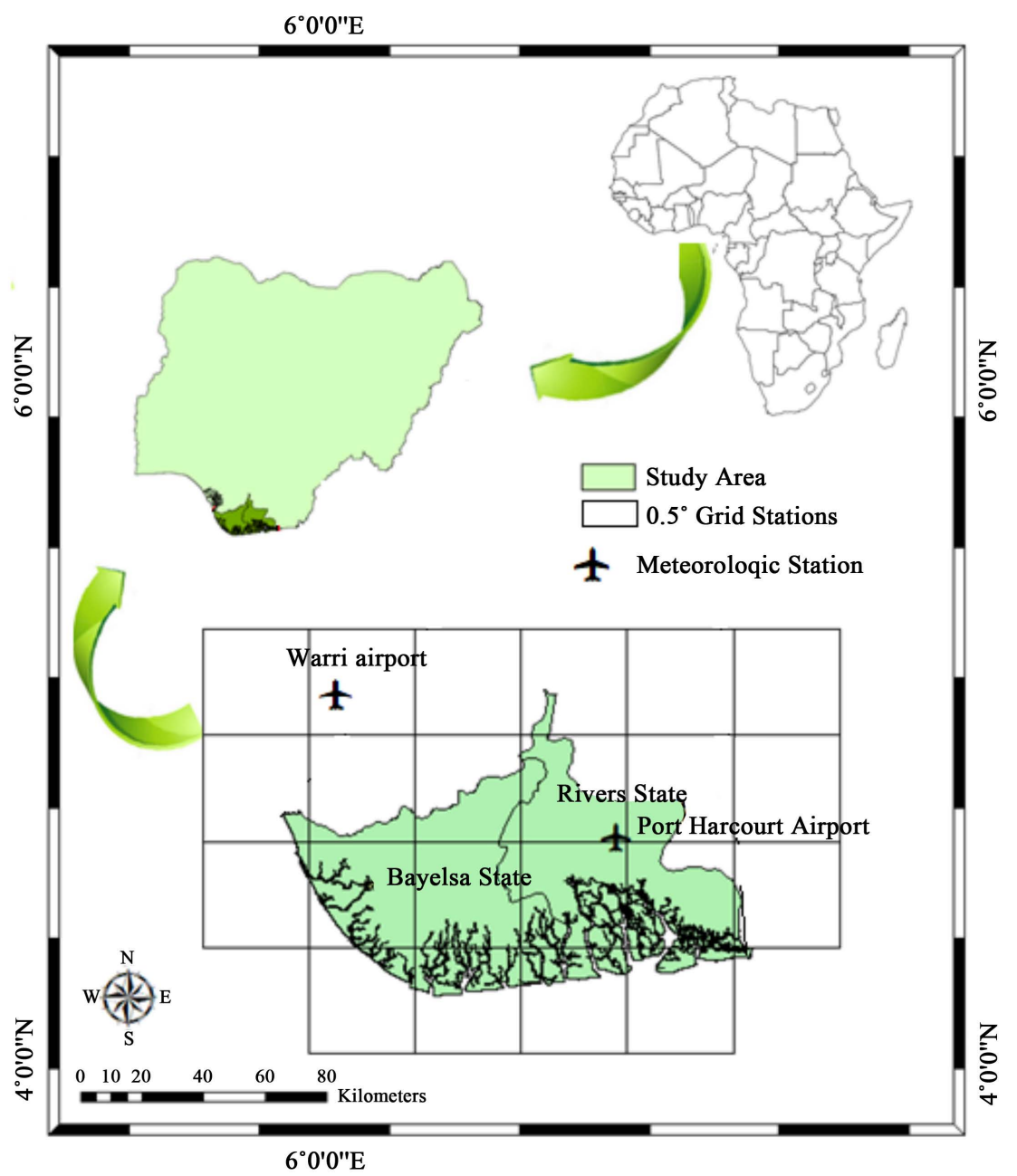

Figure 1. Map of the study area in Nigeria showing the spatial distribution of 0.50 grids.

the deflection of the moisture-laden current is often experienced in August and sometimes occurs in July or September [33] due to variations of weather.

\section{Materials and Methods}

\subsection{Data}

The gridded datasets used in this study are daily precipitation, maximum and minimum temperature datasets obtained from CRU, PGF and CFRS for the years 1980 to 2005. The observed station datasets used for this study are located at Warri and Port-Harcourt (PH) international airport, in Delta and Rivers state which were obtained from the Nigerian Meteorological Agency (NIMET).

The CRU gridded datasets are extracted from the CRU version 4.01 global climate dataset [14] and downloaded from http://www.cru.uea.ac.uk/. The PGF datasets were developed by the Princeton University Global Meteorological Forcing centre [18] and downloaded from http://hydrology.princeton.edu/data/pgf/. While the CFSR datasets were developed by the National Centres for Environ- 
mental Prediction (NCEP) [6] and downloaded from

http://cfs.ncep.noaa.gov/cfsr/.

These daily datasets were downloaded as NetCDF files and extracted at $0.5^{\circ} \times$ $0.5^{\circ}$ resulting to an equal number of grids ( 22 grids) which are spatially distributed across the study area as shown in Figure 1. The observed station data has only one observation within the study area with two other contributing stations outside the study area.

\subsection{Methods}

Two ways are generally used to compare gridded datasets with station observations: 1) Computing the average areal precipitation for each grid box from available station data and comparing them grid-to-grid [34];2) Interpolating the gridded data to station level and comparing the datasets with the observed station data [35]. Several methods such as Arithmetic mean, Thiessen polygon, isohyetal method, and gridding or distance weighting are used to estimate areal precipitation from point data. Distance weighting methods are used for gridding of the observed data to the same spatial resolution of the gridded datasets to be compared with the gauges [36]. For sparse and unevenly distributed gauges, a simple averaging of all the station data within the grid box is preferred to compute the average areal precipitation [37] [38]. Previous studies by [37] [39] [40] [41] reported that for evaluation of gridded data with in situ measurements of only one observed station within a grid box, pairwise statistical analyses between the grid point rainfall estimates and rain gauge estimates are carried out assuming that station rainfall is the average observed rainfall for the grid box. This method has been used by [35] [37] [40] [41] for the evaluation gridded datasets with observed station measurements. In this study, the performance of the three different gridded precipitation datasets was compared with single-station data located within the grid box. This is because no grid box was found to have more than one observed station.

This study is conducted in three steps. The first involves evaluating the performance of gridded datasets using statistical analysis and visual inspection, the second involves the analysis of spells among datasets. The third focused on assessing the implication of using each dataset for water resource management.

\subsubsection{Performance Evaluation of the Datasets}

The performance of gridded datasets was evaluated statistically by comparing the Seasonal variation plots of the observed and gridded datasets for the whole study period. Performance of the datasets was tested using the coefficient of correlation $\left(\mathrm{R}^{2}\right)$, the Root mean square error (RMSE) and Mean Bias (MB) and summarised in Table 1 and Table 2. The RMSE measures the global fitness of a predictive model [42]. In these equations, $y$ and $o$ are observed and simulated datasets, respectively. The correlation coefficient is measuring the degree of dependence between observations and simulated values. As the $\mathrm{R}$ value approaches 1 , the accuracy of simulated flows is higher. MAE represents the magnitude 
Table 1. Characteristics of gridded rainfall data used in this study.

\begin{tabular}{|c|c|c|c|c|c|c|c|c|c|}
\hline \multirow{2}{*}{\multicolumn{2}{|c|}{ Datasets }} & \multicolumn{2}{|c|}{ Sum } & \multicolumn{2}{|c|}{ Maximum } & \multicolumn{2}{|c|}{ Median } & \multicolumn{2}{|c|}{ Variance } \\
\hline & & $\mathrm{PH}$ & Warri & $\mathrm{PH}$ & Warri & $\mathrm{PH}$ & Warri & PH & Warri \\
\hline \multirow{4}{*}{$\begin{array}{l}\text { Precipitation } \\
\quad(\mathrm{mm})\end{array}$} & Station & 2257.5 & 2236.3 & 220.4 & 206.6 & 9.2 & 0.0 & 459.7 & 242.4 \\
\hline & CRU & 2265.1 & 2156.2 & 220.3 & 223.8 & 9.8 & 0.0 & 570.8 & 248.7 \\
\hline & PGF & 2243.7 & 2135.8 & 263.2 & 293.5 & 0.0 & 0.0 & 546.4 & 239.3 \\
\hline & CFSR & 2854.5 & 2321.0 & 147.6 & 228.9 & 8.0 & 5.2 & 81.5 & 75.0 \\
\hline & & \multicolumn{2}{|c|}{ Mean } & \multicolumn{2}{|c|}{ Maximum } & \multicolumn{2}{|c|}{ Median } & \multicolumn{2}{|c|}{ Variance } \\
\hline \multirow{4}{*}{$\begin{array}{c}\text { Maximum } \\
\text { Temperature } \\
\left({ }^{\circ} \mathrm{C}\right)\end{array}$} & Station & 31.1 & 31.8 & 44.6 & 45.5 & 31.1 & 32.0 & 12.9 & 14.0 \\
\hline & CRU & 31.1 & 31.3 & 44.4 & 45.5 & 31.3 & 31.5 & 14.1 & 14.2 \\
\hline & PGF & 31.6 & 31.8 & 43.8 & 42.0 & 26.5 & 31.6 & 4.9 & 5.4 \\
\hline & CFSR & 30.6 & 31.6 & 43.8 & 44.5 & 30.0 & 31.4 & 22.3 & 37.2 \\
\hline \multirow{4}{*}{$\begin{array}{c}\text { Minimum } \\
\text { Temperature } \\
\left({ }^{\circ} \mathrm{C}\right)\end{array}$} & Station & 22.7 & 23.2 & 31.6 & 31.8 & 22.9 & 23.2 & 4.9 & 4.6 \\
\hline & CRU & 22.6 & 22.8 & 32.1 & 31.8 & 22.6 & 22.8 & 5.5 & 5.5 \\
\hline & PGF & 23.0 & 22.3 & 27.7 & 27.8 & 14.2 & 23.2 & 1.8 & 1.8 \\
\hline & CFSR & 21.5 & 23.2 & 25.4 & 26.2 & 21.7 & 22.5 & 2.1 & 15.8 \\
\hline
\end{tabular}

Table 2. Comparison of observed gridded climate data.

\begin{tabular}{cccccccc}
\hline \multirow{2}{*}{ Datasets } & & \multicolumn{2}{c}{$\mathrm{R}^{2}$} & \multicolumn{2}{c}{ RMSE } & \multicolumn{2}{c}{ MB } \\
\cline { 3 - 8 } & & PH & Warri & PH & Warri & PH & Warri \\
\hline \multirow{2}{*}{$\begin{array}{c}\text { Precipitation } \\
(\mathrm{mm})\end{array}$} & CRU & 0.85 & 0.85 & 79.36 & 81.71 & -1.58 & 6.59 \\
& CFF & 0.86 & 0.85 & 81.33 & 82.48 & 2.87 & 8.24 \\
$\begin{array}{c}\text { Maximum } \\
\text { Temperature } \\
\left({ }^{\circ} \mathrm{C}\right)\end{array}$ & CRU & 0.57 & 0.66 & 145.58 & 116.05 & -64.94 & -6.97 \\
& PGF & 0.68 & 0.90 & 1.70 & 0.90 & 0.33 & 0.06 \\
$\begin{array}{c}\text { Minimum } \\
\text { Temperature } \\
\left({ }^{\circ} \mathrm{C}\right)\end{array}$ & CFS & 0.79 & 0.80 & 2.93 & 2.99 & 1.03 & 0.24 \\
& PGF & 0.48 & 0.61 & 1.21 & 0.92 & -0.10 & -0.02 \\
& CFSR & 0.60 & 0.37 & 1.57 & 2.19 & 1.17 & 0.89 \\
\hline
\end{tabular}

of error, and MBE shows bias from the mean. Approach to zero of these two parameters indicates that the method simulates reality well and far from zero shows high deviation and inaccuracy. Positive and negative values of MBE represent over or under estimated values respectively;

$$
\operatorname{RMSE}=\left(\frac{1}{N} \sum_{i=1}^{N_{v}}\left(y_{i}-o_{i}\right)^{2}\right)^{1 / 2}
$$

where $y$ and $o$ represent observed and predicted values respectively; and $N_{V}$ is the number of target data used for testing.

$R^{2}$ measures how the future outcomes are likely to be predicted by the model 
and are equivalent to the sample cross-correlation between predicted and observed values [42]. In this equation, the overbar denotes average values.

$$
R=\frac{\sum_{i=1}^{N_{v}}\left(y_{i}-\bar{y}\right)\left(o_{i}-\bar{o}\right)}{\sqrt{\sum_{i=1}^{N_{v}}\left(y_{i}-\bar{y}\right)^{2} \sqrt{\sum_{i=1}^{N_{v}}\left(o_{i}-\bar{o}\right)^{2}}}}
$$

The average model Bias (MB), ranging from $-\infty$ to 1 , measures the model predictive skill relative to the mean of observations [31],

$$
\text { Mean Bias }=\frac{1}{n} \sum_{1}^{n} y_{i}-o_{i}
$$

\subsubsection{Analysis of Spells Characteristics among Datasets}

The analysis of the characteristics of mean dry and wet spells lengths was conducted for the stations, using CRU, PGF and CFSR precipitation datasets to compare their ability to capture the temporal variations in the spell indices of the observed datasets. These indices are computed for the Niger Delta rainfall for a period of 26 years (1980 to 2005). Previous studies defined a day as a wet day or dry day when the amount of daily precipitation falls above or below $1 \mathrm{~mm}$ [43]. [24] [44] also defined spells as the number of consecutive rainy days with rainfall $>2.5 \mathrm{~mm}$. A wet day, in general, represents a rainy day while dry day represents a non-rainy day. Wet and dry spells are defined as extended periods of wet and dry days, respectively [20].

In this study, the R Multi-Site Rainfall Generator (RMRAINGEN) program dw.spell [45] was used for the spell length analysis. Precipitation thresholds of 1 to $3 \mathrm{~mm}$ were selected with a spell length of at least 1 day as recommended in [43] which ensure that no spell with extreme rainfall magnitude is missed out. This is because rainfall of higher magnitude over shorter durations may be disastrous [27].

\subsubsection{Standardised Precipitation Index (SPI)}

In this study, SPI was used as a water resource management tool to investigate extreme events in the selected stations. This gives an insight into the implication of the wrong choice of datasets for water resource management. SPI was developed for monitoring and defining meteorological drought and wet events from precipitation time series data [28]. SPI computes the precipitation deficit for multiple time steps and therefore facilitates the temporal analysis of drought [46]. It has also been reported that SPI provides a better spatial standardisation than any other indices. Positive SPI values show higher than median precipitation, while negative values indicate less than median precipitation [47]. SPI is calculated taking the difference of the monthly precipitation $\left(x_{i}\right)$ from the monthly mean $(\bar{x})$ then dividing by the standard deviation $(\sigma)$ [48].

$$
\mathrm{SPI}=\frac{x_{i}-\bar{x}}{\sigma}
$$




\section{Results and Discussions}

\subsection{Performance of Gridded Datasets}

The graphs comparing the distribution of the monthly mean for the station, CRU, PGF and CFSR daily precipitation, maximum and minimum temperature datasets of the study area are shown in Figures 2(a)-(f) respectively. Results of

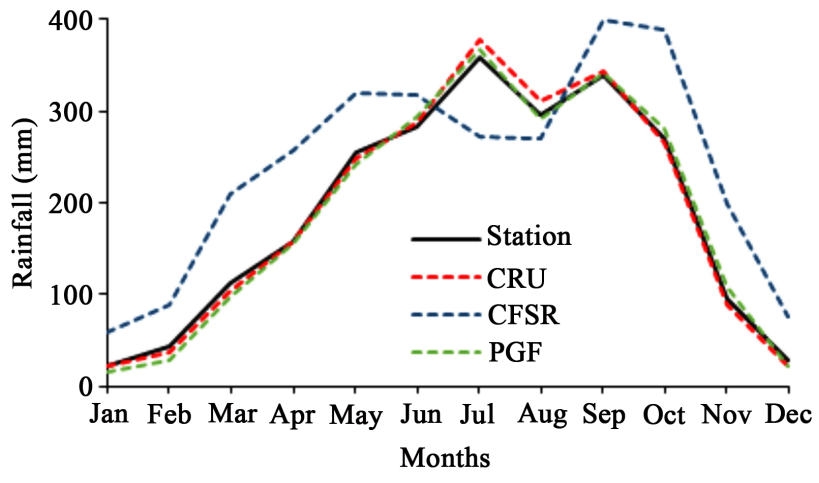

(a)

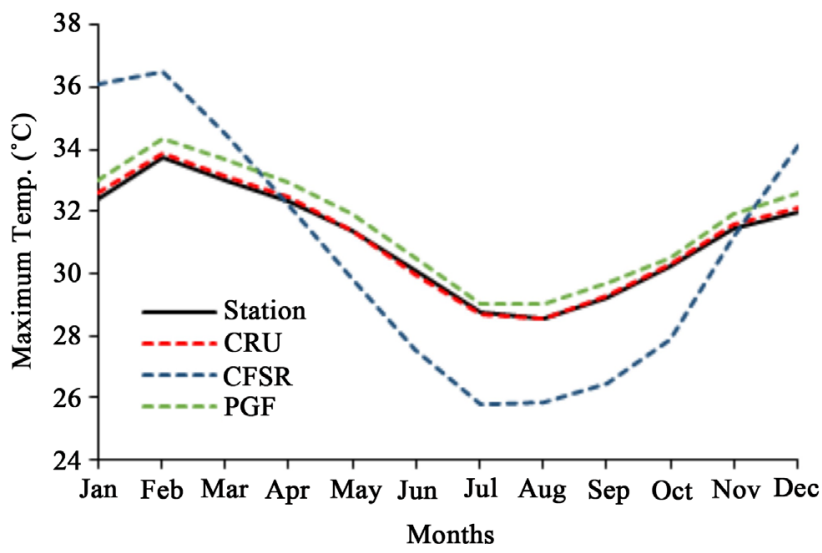

(c)

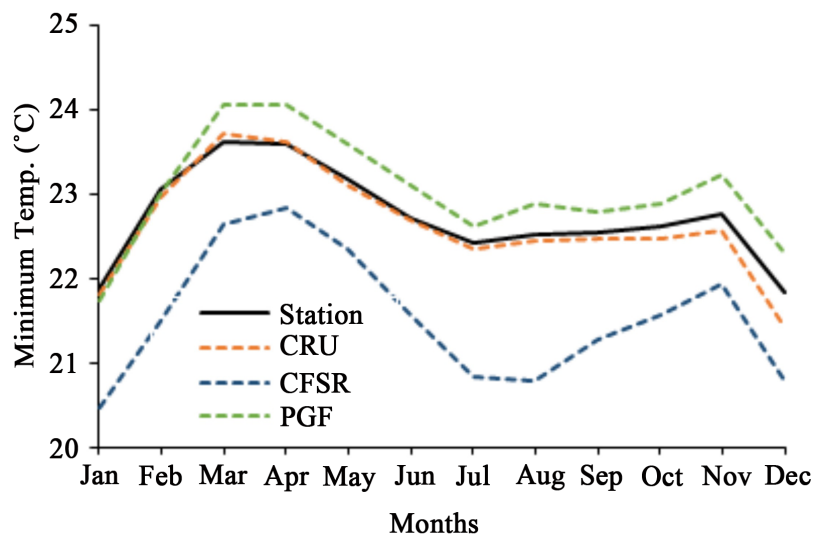

(e)

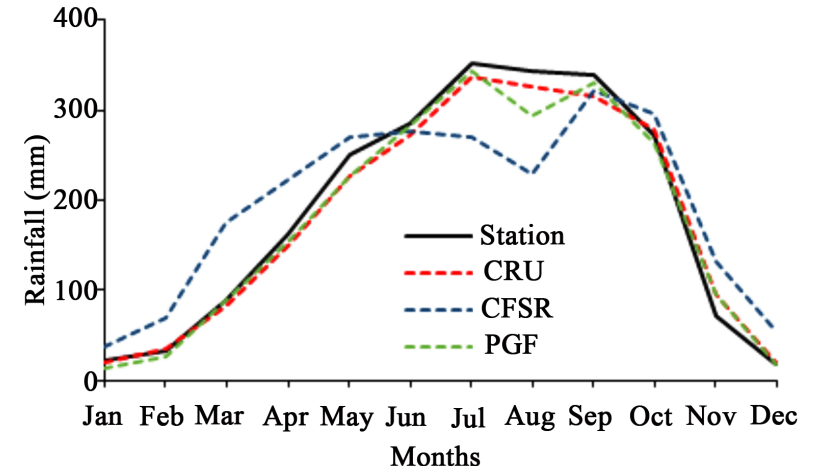

(b)

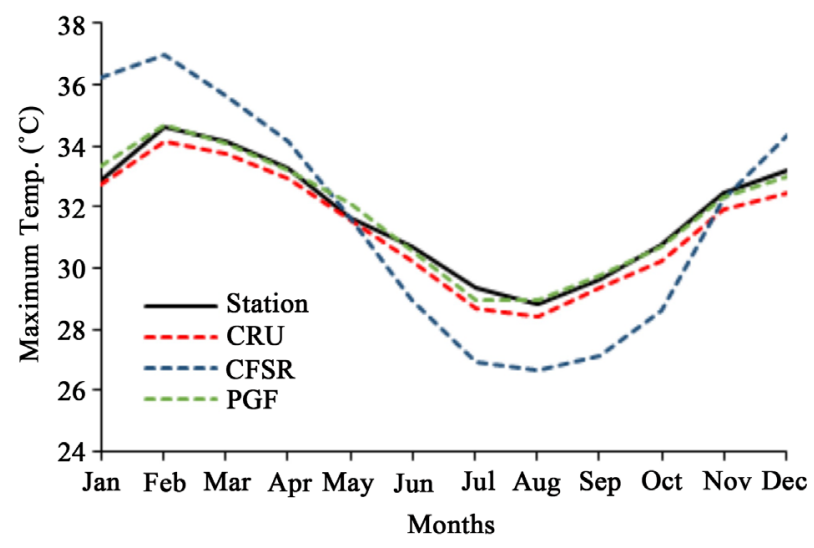

(d)

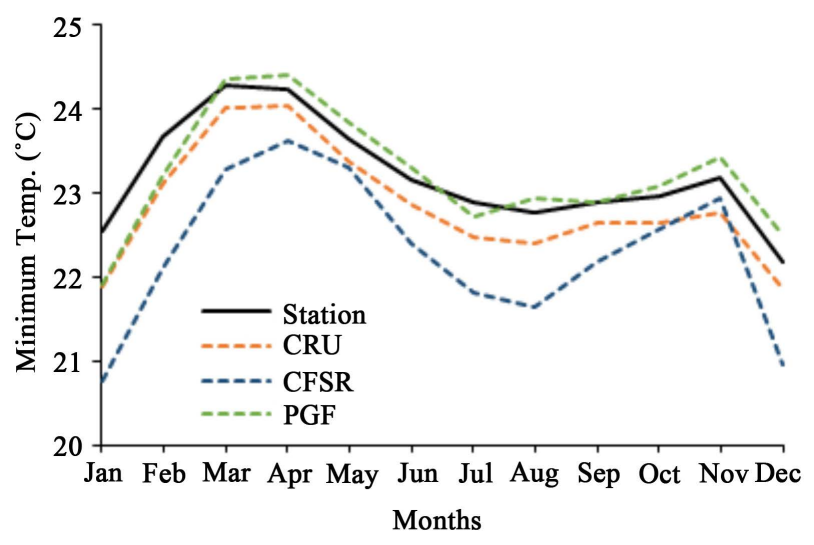

(f)

Figure 2. Seasonal variation of the annual average of observed meteorological station, CRU, PGF and CFRS datasets obtained from the same grid as the station data from 1980-2005 for (a) PH precipitation; (b) Warri precipitation; (c) $\mathrm{PH} \mathrm{T}_{\max }$; (d) Warri $\mathrm{T}_{\max }$; (e) $\mathrm{PH} \mathrm{T}_{\min }$ and (f) Warri $\mathrm{T}_{\min }$. 
descriptive statistics describing the characteristics of the datasets are also summarised in Table 1, and the statistical indicators are summarised in Table 2, respectively.

These results and figures show that the CRU and PGF datasets performed very well in depicting the study areas datasets. The Mean, Maximum, median and Variance for CRU datasets are very similar to that of the station datasets. The PGF datasets depicted the mean, maximum and variance very well in comparison with the observed datasets but highly underestimated the median values. The mean precipitation values in the CFRS datasets tend to be a bit higher while the variance, maximum and median tend to be lower in comparison with the observed precipitation. Statistical indicators in Table 2, also suggest that the RMSE values are found to be lower in CRU datasets for precipitation and minimum temperature in both stations. The $\mathrm{R}^{2}$ values of precipitation for both CRU and PGF are found to be closer to 1, except for the maximum and minimum temperature where the CFRS shows a better performance with an $\mathrm{R}^{2}$ value of 0.79 and 0.60 in Port-Harcourt station, while the CRU datasets performed better at the Warri station with an $\mathrm{R}^{2}$ value 0.9 and 0.68 in respectively. However, in all cases the datasets demonstrated satisfactory statistical performance.

Figure 2 shows the relationship between the observed station, CRU, PGF and CFRS datasets. Figure 2(a) and Figure 2(b) shows that the mean monthly distribution of CRU and PGF precipitation matches well with the observed station precipitation. The CFRS datasets consistently overestimate the study areas precipitation from September all through to June and underestimate the mean monthly precipitation from during the peak of the rainy season from June to August. In Figure 2(c) and Figure 2(d), a significant difference exists between the observed station maximum temperature and that of the CFRS in January and February and lower temperatures on the CFRS from March all through to November. In Figure 2(e) and Figure 2(f), the CFSR consistently underestimated the station minimum temperature while the PGF consistently overestimated the station minimum temperature. Therefore, as shown by statistical performance (Table $1 \&$ Table 2), and the graphical visual comparison, there is a better agreement between the monthly means of the observed station datasets and the CRU datasets which shows a better performance to that of PGF and CFRS datasets for both precipitation, maximum temperature (Tmax) and minimum temperature (Tmin) (Figure 2) even with the better performance of some of the datasets in correlation and error analysis (Table 2). This shows that results of correlation and error analysis can often be misleading in the evaluation of gridded data products as reported by [5].

\subsection{Wet Spell and Dry Spell}

Results of spell analysis for the distribution of mean monthly Dry and Wet Spell lengths are shown in Figure 3(a) \& Figure 3(c) for Port Harcourt. Figure 3(b) \& Figure 3(d) for Warri stations respectively. The figures show that the 


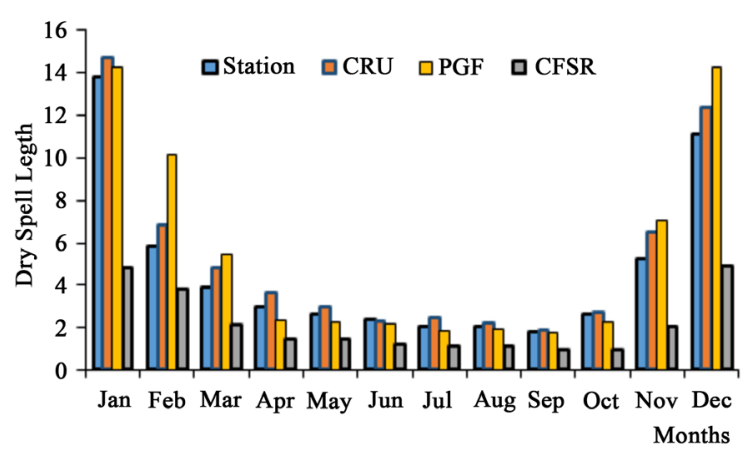

(a)

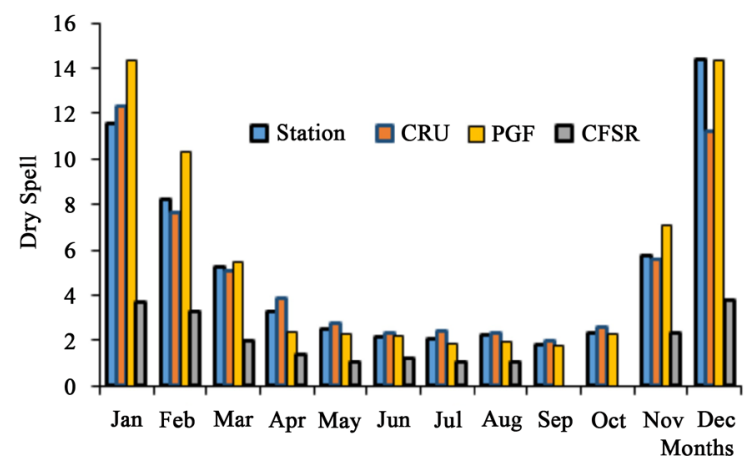

(b)

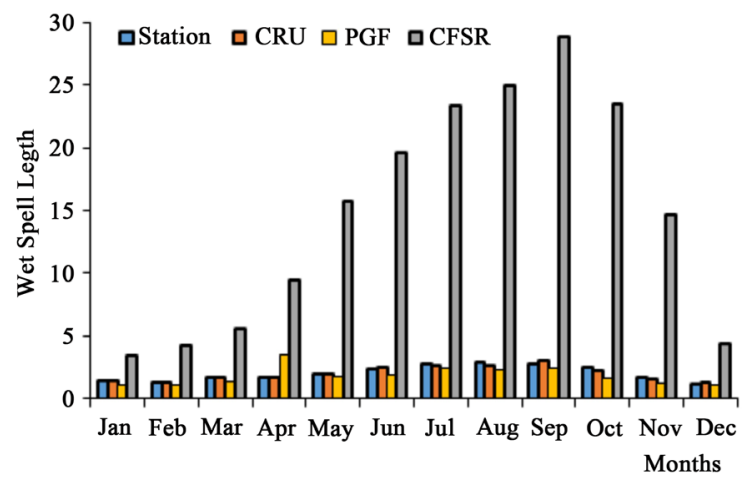

(c)

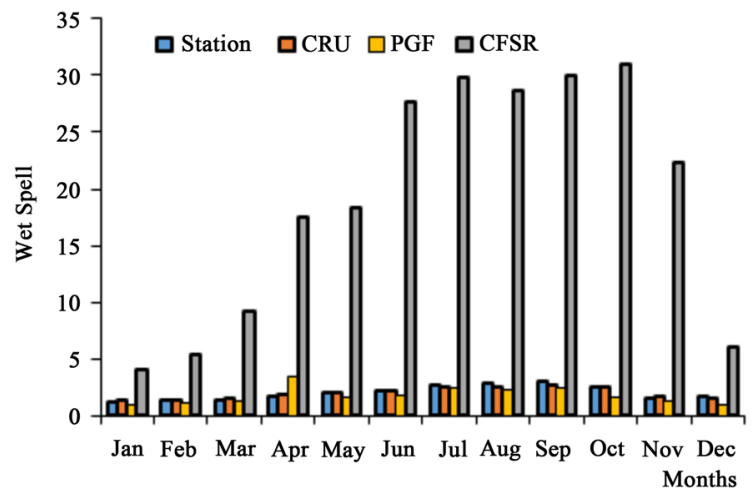

(d)

Figure 3. Comparison of Monthly Rainfall Dry Spell for (a) Port Harcourt (b) Warri and Wet Spell for (c) Port Harcourt (d) Warri observed Meteorological station data, CRU, PGF and CFRS datasets obtained from the same Grid as the station data from 1980-2005. 
distribution of CRU and PGF rainfall datasets are similar to that of the station rainfall at both study location. However, in February and December, the PGF tends to show a much longer dry spell length. The CFRS precipitation datasets consistently overestimated the mean monthly wet-spell length and underestimated the mean monthly dry-spell length. The spell length correlation was then used to assess the annual performance of the spell indices among the datasets. The correlation results summarised in Figure 4(a) and Figure 4(b) for Port Harcourt and Warri stations shows that the CRU datasets correlated better than all the remaining datasets in comparison with the observed station precipitation datasets. Therefore, the CRU can be considered as the most reliable precipitation data in term of temporal characteristics.

\subsection{The Implication for Water Resource Management}

The Standardised precipitation index for 1-year time step is calculated for the period 1980-2005 for all the four datasets (Station, CRU, PGF and CFSR). Result of the comparison of computed SPI for all the datasets is shown in Figure 5.

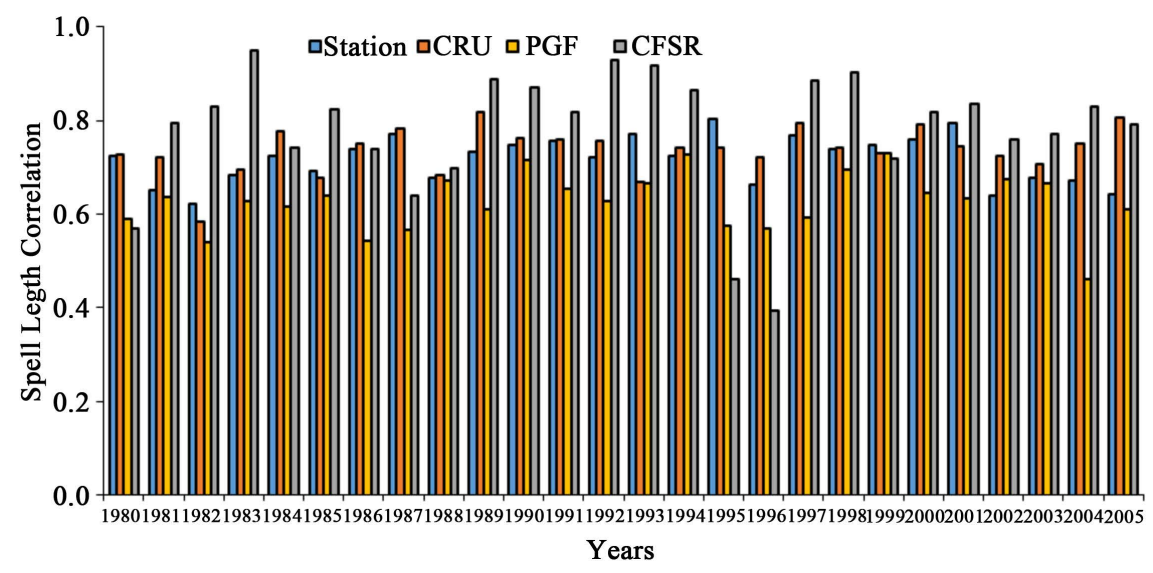

(a)

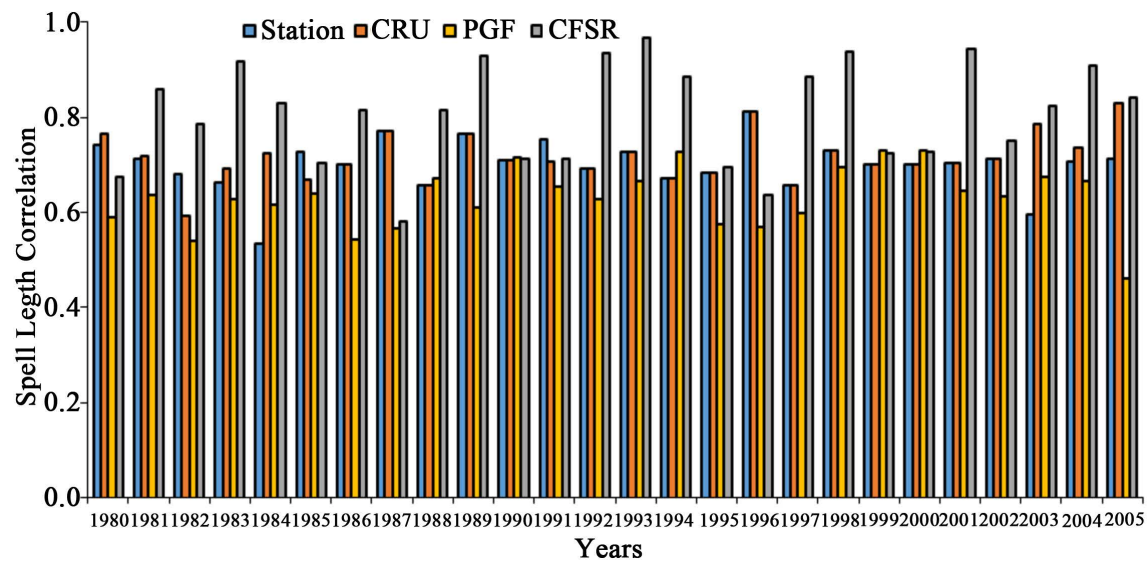

(b)

Figure 4. Spell length correlation for the observed station, CRU, PGF and CFRS datasets for (a) Port Harcourt; (b) Warri station. 


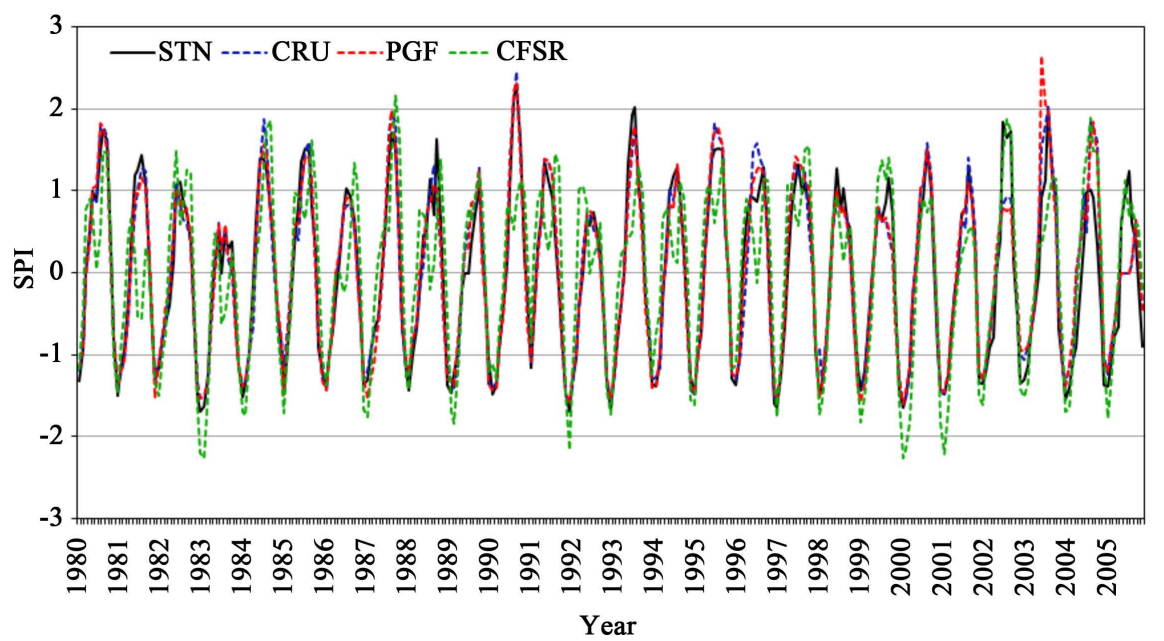

(a)

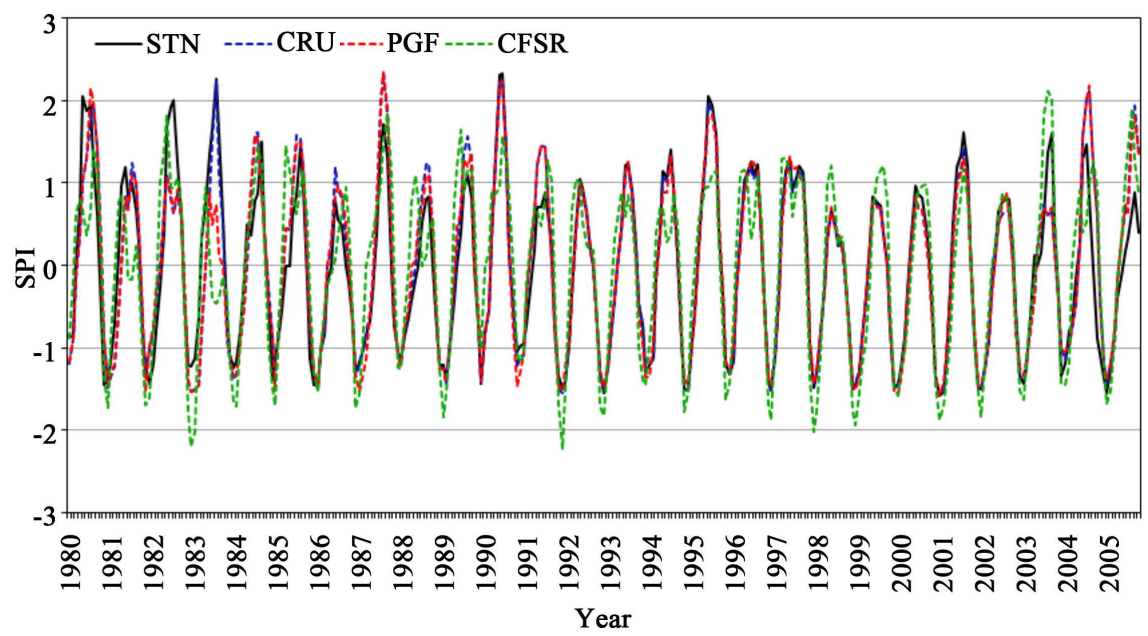

(b)

Figure 5. Computed SPI using the observed station, CRU, PGF and CFRS datasets for the periods 1980-2005 for (a) Port Harcourt; (b) Warri station.

The figure demonstrates a near perfect relationship between the SPI values (as classified by [28]) computed using the Station, CRU and PGF datasets with most of the peak values falling within the same classification across the years. However, in many years, the CFSR precipitation tends to overestimate or underestimate the SPI. In the years 1983, 1992, 2000 and 2001, the CFSR SPI estimated an extreme drought event for Port Harcourt during the dry season while the remaining datasets (Station, CRU and PGF) reveals a severe drought event based on [28] classification. The CFRS also estimated the near-normal events in the years 1982, 1986 and 1992 to moderate wet events and the very wet event in 1987 to an extremely wet event based on [28] classification. In 1991, the extreme wet event that was estimated by the Station, CRU and PGF datasets was also grossly underestimated by the CFRS to a near-normal event.

The evaluation and validation of different gridded datasets is necessary for any region in order to determine the best performing datasets in comparison 
with the real station datasets of that region before using any of the datasets for any water resource management analysis. Failure to do this results in misleading interpretation that does not depict the realities of the area.

\section{Discussions}

Several statistical techniques have been used in this study to assess the performance of three available daily gridded datasets, commonly used in the Niger Delta part of Nigeria. The study suggests that the CRU datasets replicated the observed station datasets more appropriately when different characteristics of the datasets are considered together. In Nigeria, no study has so far been conducted to assess the performance of daily gridded precipitation and temperature data products that can serve as an alternative to the unavailable station datasets. In West Africa, the only study conducted so far was in Burkina-Faso by Mahe et al., [22]. The study evaluated the ability of CRU and SIEREM (Hydro Sciences Montpellier, France) data to reproduce observed station precipitation characteristics of Burkina-Faso and to analyse the consequences of choosing each one of them on the simulated river flows in the five basins across the country. Mahe et al., [22] reported the superiority of the SIEREM precipitation in replicating the station observed precipitation product compared to CRU precipitation. AS SIEREM datasets are developed for largely Francophone African countries [49], hence they are therefore not available for Nigeria. However, comparison of the results from CRU, SIEREM and Burkina-Faso of meteorological station datasets shows that the distribution of annual rainfalls, Mean, standard deviation and minimum values are very similar [22].

Several factors contribute to the performance of gridded data products in a particular area which includes the topography of the area, method of interpolation, the quality of observed stations data, numbers of meteorological stations data and the distribution of the observed meteorological stations used in developing the datasets [50] [51]. The availability of quality long-term raw data for use in the construction of the gridded product is very crucial which is in many cases not good enough especially in developing countries where the data are often found to be nonuniform [52]. Observed meteorological time-series datasets are generally included in gauge-based gridded database preparation after checking its quality [5]. These quality control processes differ for different gridded products. In CRU, all the datasets are passed through a two-stage extensive quality control measures conducted manually and using a semi-automatic approach. The data is checked for the consistency in the first stage followed by the removal of stations or months that gives a large error during the interpolation process in the second stage [53] [54]. CRU also considers essential factors such as elevation during interpolation which consequently, enhances its ability for accurate estimation [54]. The CRU data was developed from more than 4000 weather stations distributed around the world [14] [54]. In the southern part of Nigeria alone, more than fifteen station datasets were used as contributing stations which 
could be one of the reasons for its better accuracy in the area.

Though PGF was also found to perform very well compared to CFSR in term of various characteristics. It was, however, found to underestimate the mean and median of precipitation, minimum and maximum temperature. This may cause uncertainty in the impact estimated using gridded datasets. It should be noted that no gridded dataset can correctly represent the actual station datasets [52]. Relevant dataset for a particular study can be selected based on the ability of the dataset to reconstruct specific property of the data required for such study.

\section{Conclusion}

The performances of three gridded daily precipitation and temperature products, namely, CRU, PGF and CFRS available for the study area and widely used as an alternative to observed precipitation and temperature, were evaluated in this paper. The performance of the data was evaluated using statistical indicators, comparison of time-series graphs and spells lengths analysis among datasets. The Standardised Precipitation Index (SPI) was used to determine the implication of using poor gridded precipitation data for water resource management. RMSE and MBE indicate the consistency of the CRU dataset to provide lowest errors in predicted precipitation, and PGF dataset in prediction of maximum and minimum temperatures. Results of spell analysis also show a good association between the station datasets, CRU and PGF for estimating the mean monthly distribution of Wet and Dry Spell lengths. SPI values indicate a good association between observed and CRU and PGF precipitation while the CFRS overestimate and underestimate the SPI in many years. The results revealed a clear superiority of CRU daily precipitation and temperature predictions over the other gridded products for replicating the mean monthly distribution of the station precipitation, maximum and minimum temperature in the Nigeria study area. It can, therefore, be concluded that the CRU datasets are the best performing datasets in this region and hence can confidently be used as observed datasets for further hydrological studies and future climate projection in the study area. The results obtained through the present study can be expanded to other regions in Nigeria having different climate and topography. It is expected the statistical methods used in the present study can be used in other parts of the world to select better performing data products before application of any gridded product for hydrological and climate studies in study areas with paucity of data.

\section{Acknowledgements}

The authors would like to gratefully acknowledge the Petroleum Technology and Development Fund (PTDF) Nigeria under the Overseas PhD scholarship scheme and the Scottish Government under the Climate Justice Fund Water Futures Programme, awarded to the University of Strathclyde (R.M. Kalin) for funding this research. 


\section{Conflicts of Interest}

The authors declare no conflict of interest regarding the publication of this paper.

\section{References}

[1] Wei, G., Lü, H., Crow, W.T., Zhu, Y., Wang, J. and Su, J. (2018) Evaluation of Satellite-Based Precipitation Products from IMERG V04A and V03D, CMORPH and TMPA with Gauged Rainfall in Three Climatologic Zones in China. Remote Sensing, 10, 30. https://doi.org/10.3390/rs10010030

[2] Derin, Y. and Yilmaz, K.K. (2014) Evaluation of Multiple Satellite-Based Precipitation Products over Complex Topography. Journal of Hydrometeorology, 15, 1498 1516. https://doi.org/10.1175/JHM-D-13-0191.1

[3] Worku, L.Y. (2015) Climate Change Impact on Variability of Rainfall Intensity in the Upper Blue Nile Basin. Proceedings of the International Association of Hydrological Sciences, 366, 135-136. https://doi.org/10.5194/piahs-366-135-2015

[4] IPCC Climate Change (2012) Managing the Risks of Extreme Events and Disasters to Advance Climate Change Adaptation; A Special Report of Working Groups I and II of the Intergovernmental Panel on Climate Change. Cambridge University Press, Cambridge, and New York, 582.

[5] Ahmed, K., Shahid, S., Wang, X., Nawaz, N. and Najeebullah, K. (2019) Evaluation of Gridded Precipitation Datasets over Arid Regions of Pakistan. Water (Switzerland), 11, 210. https://doi.org/10.3390/w11020210

[6] Fuka, D.R., Walter, M.T., Macalister, C., Degaetano, A.T., Steenhuis, T.S. and Easton, Z.M. (2014) Using the Climate Forecast System Reanalysis as Weather Input Data for Watershed Models. Hydrologic Process, 28, 5613-5623. https://doi.org/10.1002/hyp.10073

[7] Sun, Q., Miao, C., Duan, Q., Ashouri, H., Sorooshian, S. and Hsu, K.L. (2018) A Review of Global Precipitation Data Sets: Data Sources, Estimation, and Intercomparisons. Reviews of Geophysics, 56, 79-107. https://doi.org/10.1002/2017RG000574

[8] Bai, P. and Liu, X. (2018) Evaluation of Five Satellite-Based Precipitation Products in Two Gauge-Scarce Basins on the Tibetan Plateau. Remote Sensing, 10, 1316. https://doi.org/10.3390/rs10081316

[9] Lin, C., Maurer, E.P., Andreadis, K.M., Rosenberg, E.A., Livneh, B., Lettenmaier, D.P., Nijssen, B. and Mishra, V. (2013) A Long-Term Hydrologically Based Dataset of Land Surface Fluxes and States for the Conterminous United States: Update and Extensions. Journal of Climate, 26, 9384-9392. https://doi.org/10.1175/JCLI-D-12-00508.1

[10] Yatagai, A., Arakawa, O., Kamiguchi, K. and Kawamoto, H. (2009) A 44-Year Daily Gridded Precipitation Dataset for Asia. Sola, 5, 3-6. https://doi.org/10.2151/sola.2009-035

[11] Haylock, M.R., Hofstra, N., Klein Tank, A.M.G., Klok, E.J., Jones, P.D. and New, M. (2008) A European Daily High-Resolution Gridded Data Set of Surface Temperature and Precipitation for 1950-2006. Journal of Geophysical Research Atmospheres, 113, D20119. https://doi.org/10.1029/2008JD010201

[12] Herrera, S., Gutiérrez, J.M., Ancell, R., Pons, M.R., Frías, M.D. and Fernández, J. (2012) Development and Analysis of a 50-Year High-Resolution Daily Gridded Precipitation Dataset over Spain (Spain02). International Journal of Climatology, 32, 74-85. https://doi.org/10.1002/joc.2256 
[13] Schiemann, R., Liniger, M.A. and Frei, C. (2010) Reduced Space Optimal Interpolation of Daily Rain Gauge Precipitation in Switzerland. Journal of Geophysical Research Atmospheres, 115, 1-18. https://doi.org/10.1029/2009JD013047

[14] Harris, I., Jones, P.D., Osborn, T.J. and Lister, D.H. (2014) Updated High-Resolution Grids of Monthly Climatic Observations-The CRU TS3.10 Dataset. International Journal of Climatology, 34, 623-642. https://doi.org/10.1002/joc.3711

[15] Steurer, P.M., Peter, T.C., Heim, R. and Karl, T.R. (1992) The Global Historical Climatology Network: Long-Term Monthly Temperature, Precipitation, Sea Level Pressure, and Station Pressure Data.

[16] Chen, M., Xie, P., Janowiak, J.E. and Arkin, P.A. (2002) Global Land Precipitation: A 50-Yr Monthly Analysis Based on Gauge Observations. Journal of Hydrometeorology, 3, 249-266. https://doi.org/10.1175/1525-7541(2002)003<0249:GLPAYM>2.0.CO;2

[17] Saha, S., Moorthi, S., Pan, H.-L., Wu, X., Wang, J., Nadiga, S., Tripp, P., Kistler, R., Woollen, J., Behringer, D., et al. (2010) The NCEP Climate Forecast System Reanalysis. Bulletin of the American Meteorological Society, 91, 1015-1058. https://doi.org/10.1175/2010BAMS3001.1

[18] Sheffield, J., Goteti, G. and Wood, E.F. (2006) Development of a 50-Year HighResolution Global Dataset of Meteorological Forcings for Land Surface Modeling. Journal of Climate, 19, 3088-3111. https://doi.org/10.1175/JCLI3790.1

[19] Schneider, U., Becker, A., Finger, P., Meyer-Christoffer, A., Ziese, M. and Rudolf, B. (2014) GPCC's New Land Surface Precipitation Climatology Based on QualityControlled in Situ Data and Its Role in Quantifying the Global Water Cycle. Theoretical and Applied Climatology, 115, 15-40.

https://doi.org/10.1007/s00704-013-0860-x

[20] Chaudhuri, A.H., Ponte, R.M. and Nguyen, A.T. (2014) A Comparison of Atmospheric Reanalysis Products for the Arctic Ocean and Implications for Uncertainties in Air-Sea Fluxes. Journal of Climate, 27, 5411-5421.

https://doi.org/10.1016/j.jhydrol.2017.01.023

[21] Rahman, S.H., Sengupta, D. and Ravichandran, M. (2009) Variability of Indian Summer Monsoon Rainfall in Daily Data from Gauge and Satellite. Journal of Geophysical Research Atmospheres, 114. https://doi.org/10.1029/2008JD011694

[22] Mahe, G., New, M., Paturel, J.E., Cres, A., Dezetter, A., Boyer, J.F., Rouche, N., Servat, E., New, M., Paturel, J.E., et al. (2008) Comparing Available Rainfall Gridded Datasets for West Africa and the Impact on Rainfall-Runoff Modelling Results, the Case of Burkina-Faso. Water SA, 34, 529-536. http://www.wrc.org.za https://doi.org/10.4314/wsa.v34i5.180650

[23] Revadekar, J.V. and Preethi, B. (2012) Statistical Analysis of the Relationship between Summer Monsoon Precipitation Extremes and Food Grain Yield over India. International Journal of Climatology, 32, 419-429. https://doi.org/10.1002/joc.2282

[24] Ratan, R. and Venugopal, V. (2013) Wet and Dry Spell Characteristics of Global Tropical Rainfall. Water Resources Research, 49, 3830-3841. https://doi.org/10.1002/wrcr.20275

[25] Singh, N. and Ranade, A. (2010) The Wet and Dry Spells across India during 19512007. Journal of Hydrometeorology, 11, 26-45. https://doi.org/10.1175/2009JHM1161.1

[26] Singh, D., Tsiang, M., Rajaratnam, B. and Diffenbaugh, N.S. (2014) Observed Changes in Extreme Wet and Dry Spells during the South Asian Summer Monsoon Season. Nature Climate Change, 4, 456-461. https://doi.org/10.1038/nclimate2208 
[27] Vinnarasi, R. and Dhanya, C.T. (2016) Changing Characteristics of Extreme Wet and Dry Spells of Indian Monsoon Rainfall. Journal of Geophysical Research: Atmospheres, 121, 2146-2160. https://doi.org/10.1002/2015JD024310

[28] Mckee, T.B., Doesken, N.J. and Kleist, J. (1993) The Relationship of Drought Frequency and Duration to Time Scales. AMS 8 th Conference on Applied Climatology, January 1993, 179-184.

[29] Ashouri, H., Nguyen, P., Thorstensen, A., Hsu, K., Sorooshian, S. and Braithwaite, D. (2016) Assessing the Efficacy of High-Resolution Satellite-Based Persiann-CDR Precipitation Product in Simulating Streamflow. Journal of Hydrometeorology, 17, 2061-2076. https://doi.org/10.1175/JHM-D-15-0192.1

[30] Chaudhary, S., Dhanya, C.T. and Vinnarasi, R. (2017) Dry and Wet Spell Variability during Monsoon in Gauge-Based Gridded Daily Precipitation Datasets over India. Journal of Hydrology, 546, 204-218. https://doi.org/10.1175/JCLI-D-13-00424.1

[31] Willmott, C.J. and Matsuura, K. (2006) On the Use of Dimensioned Measures of Error to Evaluate the Performance of Spatial Interpolators. International Journal of Geographical Information Science, 20, 89-102. https://doi.org/10.1080/13658810500286976

[32] Willmott, C. and Matsuura, K. (2005) Climate Research. Climate Research, 30, 79-82. http://www.int-res.com https://doi.org/10.3354/cr030079

[33] Amadi, A.N. (2014) Impact of Gas-Flaring on the Quality of Rain Water, Groundwater and Surface Water in Parts of Eastern Niger Delta, Nigeria. Journal of Geosciences and Geomatics, 2, 114-119.

[34] Yin, H., Donat, M.G., Alexander, L.V. and Sun, Y. (2015) Multi-Dataset Comparison of Gridded Observed Temperature and Precipitation Extremes over China. International Journal of Climatology, 35, 2809-2827. https://doi.org/10.1002/joc.4174

[35] Hu, Z., Hu, Q., Zhang, C., Chen, X. and Li, Q. (2016) Evaluation of Reanalysis, Spatially Interpolated and Satellite Remotely Sensed Precipitation Data Sets in Central Asia. Journal of Geophysical Research Atmospheres, 121, 5648-5663. https://doi.org/10.1002/2016JD024781

[36] Prakash, S., Gairola, R.M. and Mitra, A.K. (2015) Comparison of Large-Scale Global Land Precipitation from Multisatellite and Reanalysis Products with Gauge-Based GPCC Data Sets. Theoretical and Applied Climatology, 121, 303-317. https://doi.org/10.1007/s00704-014-1245-5

[37] Nkiaka, E., Nawaz, N.R. and Lovett, J.C. (2017) Evaluating Global Reanalysis Precipitation Datasets with Rain Gauge Measurements in the Sudano-Sahel Region: Case Study of the Logone Catchment, Lake Chad Basin. Meteorological Applications, 24, 9-18. https://doi.org/10.1002/met.1600

[38] Kursinski, A.L. and Zeng, X. (2006) Areal Estimation of Intensity and Frequency of Summertime Precipitation over a Midlatitude Region. Geophysical Research Letters, 33, 1-5. https://doi.org/10.1029/2006GL027393

[39] Salman, S.A., Shahid, S., Ismail, T., Ahmed, K. and Wang, X.J. (2018) Selection of Climate Models for Projection of Spatiotemporal Changes in Temperature of Iraq with Uncertainties. Atmospheric Research, 213, 509-522. https://doi.org/10.1016/j.atmosres.2018.07.008

[40] Robeson, S.M. and Ensor, L.A. (2006) Daily Precipitation Grids for South America. Bulletin of the American Meteorological Society, 86, 1567-1570. https://doi.org/10.1175/1520-0477(2006)87[1095:DPGFSA]2.0.CO;2

[41] Worqlul, A.W., Maathuis, B., Adem, A.A., Demissie, S.S., Langan, S. and Steenhuis, 
T.S. (2014) Comparison of Rainfall Estimations by TRMM 3B42, MPEG and CFSR with Ground-Observed Data for the Lake Tana Basin in Ethiopia. Hydrology and Earth System Sciences, 18, 4871-4881. https://doi.org/10.5194/hess-18-4871-2014

[42] Willmott, C.J. (1981) On the Validation of Models. Physical Geography, 2, 184-194. https://doi.org/10.1080/02723646.1981.10642213

[43] Sushama, L., Ben Said, S., Khaliq, M.N., Nagesh Kumar, D. and Laprise, R. (2014) Dry Spell Characteristics over India Based on IMD and Aphrodite Datasets. Climate Dynamics, 43, 3419-3437. https://doi.org/10.1007/s00382-014-2113-9

[44] Dash, S.K., Kulkarni, M.A., Mohanty, U.C. and Prasad, K. (2009) Changes in the Characteristics of Rain Events in India. Journal of Geophysical Research Atmospheres, 114, 1984-2012. https://doi.org/10.1029/2008JD010572

[45] Cordano, E. (2016) Package "RMRAINGEN" (R Multi-Site RAINfall GENeretor): A Package to Generate Daily Time Series of Rainfall from Monthly Mean Values. CRAN, 23. https://github.com/cran/RMRAINGEN/blob/master/R/dw.spell.RD

[46] Shahid, S. (2008) Spatial and Temporal Characteristics of Droughts in the Western Part of Bangladesh. Hydrological Processes. Wiley Interscience, 2274, 2267-2274.

[47] Lloyd-Hughes, B. and Saunders, M.A. (2002) A Drought Climatology for Europe. International Journal of Climatology, 22, 1571-1592. https://doi.org/10.1002/joc.846

[48] Komuscu, A.U. (1999) Using the SPI to Analyze Spatial and Temporal Patterns of Drought in Turkey Using the SPI to Analyze Spatial and Temporal Patterns of Drought in Turkey. Drought Network News, 11, 6-13.

[49] Mahe, G., L'Hote, Y., Olivry, J. and Wotling, G. (2001) Tendances et discontinuités dans des séries de pluies régionales en Afrique de l'Ouest et Centrale: 1951-1989. Hydrological Sciences Journal, 46, 211-226. https://doi.org/10.1080/02626660109492817

[50] Fu, Y., Xia, J., Yuan, W., Xu, B., Wu, X., Chen, Y. and Zhang, H. (2016) Assessment of Multiple Precipitation Products over Major River Basins of China. Theoretical and Applied Climatology, 123, 11-22. https://doi.org/10.1007/s00704-014-1339-0

[51] Sun, Q., Miao, C., Duan, Q., Kong, D., Ye, A., Di, Z. and Gong, W. (2014) Would the "Real" Observed Dataset Stand Up? A Critical Examination of Eight Observed Gridded Climate Datasets for China. Environmental Research Letters, 9, Article ID: 055007. https://doi.org/10.1088/1748-9326/9/1/015001

[52] Salman, S.A., Shahid, S., Ismail, T., Al-Abadi, A.M., Wang, X. and Chung, E.S. (2019) Selection of Gridded Precipitation Data for Iraq Using Compromise Programming, Measurement. Journal of the International Measurement Confederation, 132, 87-98. https://doi.org/10.1016/j.measurement.2018.09.047

[53] New, M., Lister, D., Hulme, M. and Makin, I. (2002) A High-Resolution Data Set of Surface Climate over Global Land Areas. Climate Research, 21, 1-25. https://doi.org/10.3354/cr021001

[54] Jones, P.D. and Harris, I.C. (2008) Climatic Research Unit (CRU) Time-Series Datasets of Variations in Climate with Variations in Other Phenomena. NCAS British Atmospheric Data Centre. http://catalogue.ceda.ac.uk/uuid/3f8944800cc48e1cbc29a5ee12d8542d 